（色材，57[10]552-557. 1984）

\title{
燐酸垔鉊系化成処理特性に及ぼす自動車用鋼板 の表面キャラクタリゼーション効果
}

佐藤登*

\author{
要旨
}

自動車用片面電気亜鉛メッキ鋼板（EG）及び片面塗装鋼板 (PC) の冷延面に対する燐酸亜鉛系化成処理に関

して，鋼板表面のキャラクタリゼーション効果を検討した。

EG の場合には冷延面の亜鉛濃度が化成処理性に影響を及ぼすが，业鉛除去として電気化学的処理法を適用す れば良好な化成処理性が得られる。

PC の場合にはジンクリッチプライマー麿付け過程で履歴を受け，その結果化成処理性に影響を及ぼすが特定 の表面仕上げを適用することによって冷延鋼板と同レベルとなる。しかし PC の場合でも製造プロセスによって は，表面仕上げを適用しなくても良好な化成処理性を示するのもある。これは主に表面に存在する Ni 成分に負 らところが大きいと考光られる。

\section{1. 緒言}

自動車工業に括ける鋼板材料の化成処理性は, 塗装外 観だけでなく自動車の耐久性のひとつである耐食性に影 響を及ぼす大きな因子である。るた昨今，自動車に適用 されている表面処理鋼板は Perforation 対策を中心炕， 数多くの種類を有していることも事実である。したがっ て表面処理鋼板の製造プロセスもその種類に応じまちま ちで，鋼板の表面性状も製造プロセスの履歴によって左 右され，その結果固有の表面キャラクタリゼーションを 形成する。

一方，燐酸亚鉛系の結晶形成過程は以下のと拈りであ る。

$$
\begin{aligned}
& \mathrm{Zn}\left(\mathrm{H}_{2} \mathrm{PO}_{4}\right)_{2} \longrightarrow \mathrm{ZnHPO}_{4}+\mathrm{H}_{3} \mathrm{PO}_{4} \\
& 3 \mathrm{ZnHPO}_{4} \stackrel{\mathrm{H}_{2} \mathrm{O}}{\longrightarrow} \mathrm{Zn}_{3}\left(\mathrm{PO}_{4}\right)_{2} \cdot 4 \mathrm{H}_{2} \mathrm{O}+\mathrm{H}_{3} \mathrm{PO}_{4} \\
& \text { <結晶 : Hopeite> } \\
& \mathrm{Fe}+2 \mathrm{H}_{3} \mathrm{PO}_{4} \longrightarrow \mathrm{Fe}\left(\mathrm{H}_{2} \mathrm{PO}_{4}\right)_{2}+2 \mathrm{H}^{+} \\
& \text {<鋼板> } \\
& \mid 0<\text { 酸化剂 }>\mid 0<\text { 酸化剂 }> \\
& \mathrm{H}_{2} \mathrm{O}
\end{aligned}
$$

昭和 59.5.22 受理

* 本田技研工業(株)鈴鹿製作所

三重県鈴鹿市平田町 1907 (广513)

$$
\begin{aligned}
& \mathrm{FePO}_{4} \downarrow+\mathrm{H}_{3} \mathrm{PO}_{4}+1 / 2 \mathrm{H}_{2} \mathrm{O} \\
& <\text { スラッジ> }
\end{aligned}
$$

$$
\begin{aligned}
& \mathrm{Fe}+2 \mathrm{Zn}\left(\mathrm{H}_{2} \mathrm{PO}_{4}\right)_{2} \stackrel{\mathrm{H}_{2} \mathrm{O}}{\mathrm{O}} \mathrm{Zn}_{2} \mathrm{Fe}\left(\mathrm{PO}_{4}\right)_{2} \cdot 4 \mathrm{H}_{2} \mathrm{O} \\
& \text { <鋼板> <結晶: Phosphophyllite> } \\
& +2 \mathrm{H}_{3} \mathrm{PO}_{4}+\mathrm{H}_{2} \mathrm{O}
\end{aligned}
$$

すなわち（2）及び（5）式より Hopeite $(\mathrm{H})$ と Phosphophyllite (P) の結晶成分が生成する。一般的に 後者の方が前者に比較し化学的に安定で結晶質的には良 好であることから ${ }^{1)}, \mathrm{P} / \mathrm{P}+\mathrm{H}$ の比率で $\mathrm{P}$ 比を定義し化 成処理性のレベルを議論することが不可欠である。(5) 式の反応からわかるよらに, 鋼板側からの $\mathrm{Fe}$ 供給が $\mathrm{P}$ 比を向上させるらえでのポイントになるが，鋼板製造プ 口セスの履歴から生じる鋼板表面成分は非常に大きな影 響を及ぼす。化成処理性が鋼板表面成分から受ける影響 度については, 最近の表面解析装置の普及によって様及 な観点から解析された研究報告が数多く見られる ${ }^{2111 。}$

ここでは代表的な表面処理鋼板の化成処理性につい て，鋼板表面のキャラクタリゼーションとの関連から述 ベることにする。 


\section{2. 実}

験

\section{1 供試鋼板材料}

実験に使用した鋼板材料は以下の 3 種類である。

(1) 片面電気亜鉛メッキ鋼板 (目付量 $30 \mathrm{~g} / \mathrm{m}^{2}$ )

(2) 片面塗装鋼板（叙装膜厚 $10 \sim 15 \mu$ )

(3) 冷間圧延鋼板（上記(1)及び(2)の比較材)

\section{2 化成処理条件}

燐酸亜鉛系によるディッピング方式にて， $53^{\circ} \mathrm{C} \times 120$ sec. 処理により実施した。

\section{3 評価方法}

片面表面処理鋼板の場合は通常，車体外板の外面が非 処理面, 内面が処理面に対応するため非処理面すなわち 鉄面に対し検討した。

2.3.1 化成皮膜結晶の評価

結晶形態……走查型電子顕微鏡による SEM 像解析

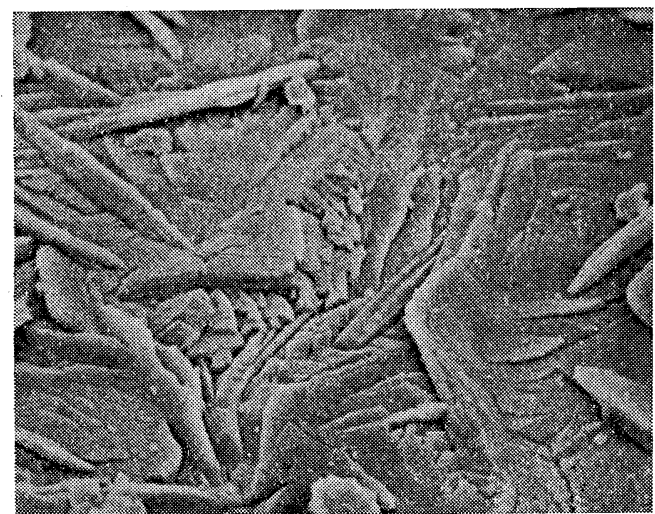

a) EG-A

$\mathrm{C} / \mathrm{W}: 2.8 \mathrm{~g} / \mathrm{m}^{2} \quad$ P $: 18 \%$

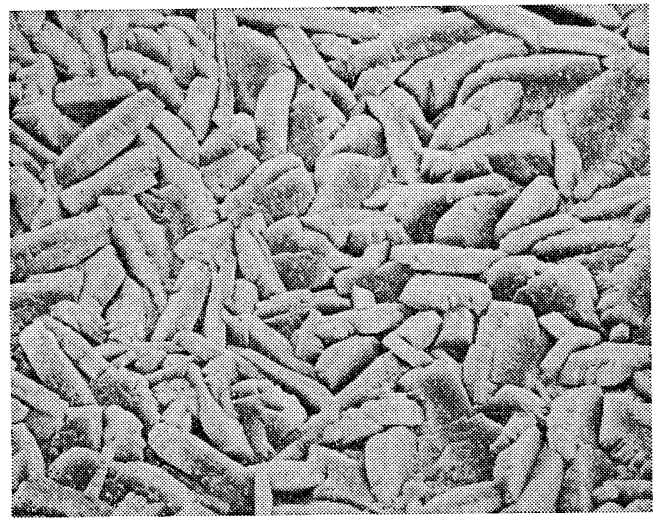

c) $\mathrm{EG}-\mathrm{C}$

$\mathrm{C} / \mathrm{W}: 2.6 \mathrm{~g} / \mathrm{m}^{2} \quad \mathrm{P}: 87 \%$
結晶重量……クロム酸溶解法に上る重量測定

結晶成分……X 線回折法による $\mathrm{P}$ 比解析

2.3.2 鋼板原板表面の評価

表面形態……走查型電子顕微鏡に上る SEM 像解析 表面成分……次イオン質量分析 SIMS に上る成分 系の解析

\section{3. 結果と考察}

3. 1 片面電気亜鉛メッキ鋼板 (Electrolytic Galvanized Steel の略により以下 EG とする)の化成処 理性

基本的には片面のみに純亜鉛がメッキされるのである が，実際には電気メッキ時の亜鉛の回り込みによって冷 延面側にも付着されていく場合がある。そこで，

a) EG-A……残留业鉛として冷延側に $1 \mathrm{~g} / \mathrm{m}^{2}$ 程度 含有する $E G$

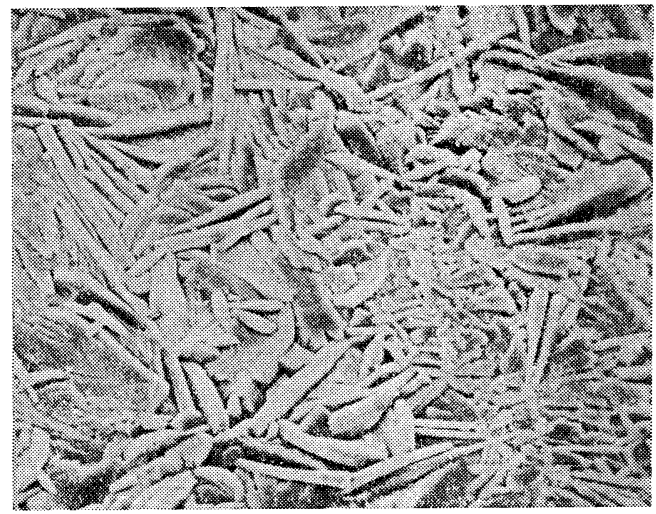

b) $E G-B$

$\mathrm{C} / \mathrm{W}: 2.3 \mathrm{~g} / \mathrm{m}^{2} \quad \mathrm{P}: 62 \%$

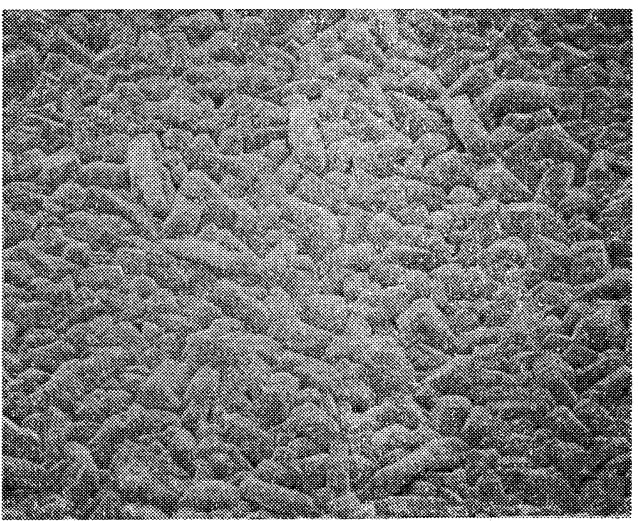

d) $\mathrm{SPC}$

$\mathrm{C} / \mathrm{W}: 2.7 \mathrm{~g} / \mathrm{m}^{2} \quad \mathrm{P}: 89 \%$

Photo. 1. Zinc phosphating property on steel side of Electrolytic Galvanized Steels that have different zinc concentration $(\mathrm{SEM} \times 1,500)$ 


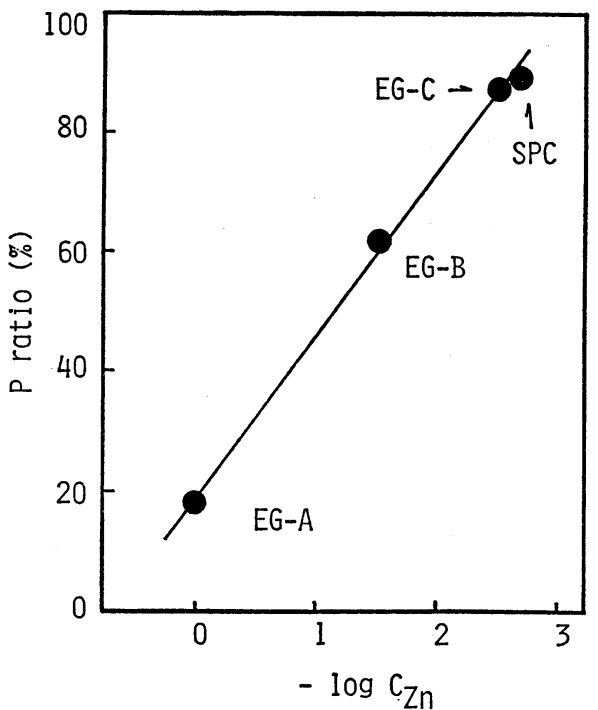

Fig. 1. Relationship between zinc concentration of steel surface and $P$ ratio

b ）EG-B……残留亜鉛抑制法として製造 プロセス 中にて亜鉛の回り込みを少なくするため物理的にシール ドし，冷延側の亜鉛濃度を $3 \times 10^{-2} \mathrm{~g} / \mathrm{m}^{2}$ 程度にコント ロールした EG

c） EG-C……残留刺鉛除去法として製造 プロセス 中にて電気化学的に亜鉛の離脱を促進させ, 冷延側の亜 鉛濃度を $3 \times 10^{-3} \mathrm{~g} / \mathrm{m}^{2}$ 程度にコントロールした EG

d) SPC……記 3 種類 の EG に 対する比較用冷延 鋼板。表面の亜鈶濃度は $2 \times 10^{-3} \mathrm{~g} / \mathrm{m}^{2}$ 程度

以上 4 種類について鋼板表面の亜鉛濃度の影響を検討 した。SEM, 結晶重量 (Coating Weight 以下 $\mathrm{C} / \mathrm{W}$ と 表現する) 及び P 比の結果を写真-1 亿示した。また残留 亜鉛濃度と P 比との相関々係を図-1 に示した。

この結果，鋼板表面の化成処理性は残留亜鉛濃度によ り大きく影響され，特に結晶形態及び $\mathrm{P}$ 比に和いてその 傾向が著しいことがわかる。これは結晶形成過程中の (5) 式の反応に抢いて，鋼板側から供給されるべき $\mathrm{Fe}$ が鋼板表面の $\mathrm{Zn}$ の存在により阻害され $\mathrm{Zn}_{2} \mathrm{Fe}\left(\mathrm{PO}_{4}\right)_{2}$ $.4 \mathrm{H}_{2} \mathrm{O}$ の生成が著しく遅れ, 主に $\mathrm{Zn}_{3}\left(\mathrm{PO}_{4}\right)_{2} \cdot 4 \mathrm{H}_{2} \mathrm{O}$ が 優先的に形成されるためである。

したがって電気亜鉛メッキ系の鋼板においては, 残留 亜鉛のコントロールが非常に 重要である。図-1 に示し たように鋼板製造プロセス中にて電気化学的に亜鉛を除 去し，その表面濃度を $3 \times 10^{-3} \mathrm{~g} / \mathrm{m}^{2}$ 以下に抑制するこ とによって標準の冷延鋼板と同等の皮膜結晶が得られる ことが明らかになった。
3.2 片面塗装鋼板 (Pre-Coated Steel の略により以 下 PC とする) の化成処理性

塗装鋼板の代表的なものとしてはジンクリッチプライ マーを焼付け塗装したものがある。基本的には片面のみ に塗膜層が形成されるのであるが，実際にはジンクリッ チプライマー焼付计過程が冷延面側にも影響を及ぼす場 合がある。そこで,

e ） PC-A……冷延面の製造履歷による影響を除去す る目的で表面をブラッシングした PC

f ) PC-B …‥e ) と同一塗装鋼板で, 冷延面のブラ ッシングレベルを強化した PC

g) PC-C…‥e e), f ) 之同一塗装鋼板で, 冷延面の ブラッシングレベルをf）以上に強化した PC

h ） PC-D …e e ) ～g ） とは異なる塗装鋼板（但し， ジンクリッチプライマー滁装鋼板の一種）で, 冷延面の 表面仕上げは $\mathrm{g}$ ) と同一の PC

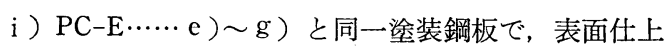
ゲのブラッシングの代りに研削方式を適用した PC

j ） PC-F……e ）～i ）とは異なる 塗装鋼板（但し, ジンクリッチプライマー塗装鋼板の一種) で, 表面仕上 げとしてのブラッシングや研削方式を適用していない PC

以上 6 種類について鋼板表面の受ける製造履歴と表面 仕上げの影響を検討した。 $\mathrm{SEM} ， \mathrm{C} / \mathrm{W}$ 及び $\mathrm{P}$ 比の結果 を写真-2 及び写真-3 と示した。

e ） h）で得られた結晶の成分は $\mathrm{P}$ 比が $90 \sim 91 \%$ と ほとんぞが $\mathrm{Zn}_{2} \mathrm{Fe}\left(\mathrm{PO}_{4}\right)_{2} ・ 4 \mathrm{H}_{2} \mathrm{O}$ であり，質的には良好 である。しかし，e）のSEM とよると部分的には結晶 の形成されていない部分がある。表面仕上げのレベルを e ) $\rightarrow$ f ) $\rightarrow$ g ） と段階的に強化していくと，この結晶未 形成部が確実に減っていくことが確認できる。これは塗 装鋼板製造過程で泠延面の受けた履歴が，化成処理段階 で結晶形成を阻害していること，そしてこのような影響 は最終の表面仕上げのレベルによってある程度除去でき ることを意味している。また e ) h ）の結晶形態とし ては個々の結晶サイズが 10〜15 $\mu$ と大きく, 写真 -1 の d）に示した冷延鋼板のそれと比較するとかなりの差異 がある。置田らの報告によると, 化成処理結晶サイズの 大きなるのは応力やチッピングを受けると結晶にクラッ クが入ったり結晶が割れたりするいわゆるスリップバン ド現象を発生しやすいことが明らかにされている10)。し たがって結晶サイズは緻密なほど良好というわけである が，e）～h）に沶いては結晶を繳密にさせる核が不足 しているために大きな結晶を形成すると考兄られる。 これに対し，同一塗装鋼板でも表面仕上げの方式を变 


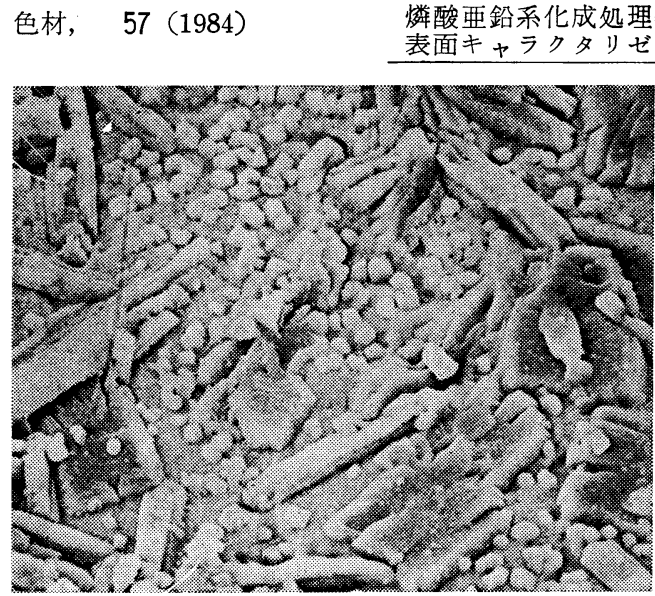

e ) $\mathrm{PC}-\mathrm{A}$

$\mathrm{C} / \mathrm{W}: 2.5 \mathrm{~g} / \mathrm{m}^{2} \quad \mathrm{P}: 90 \%$

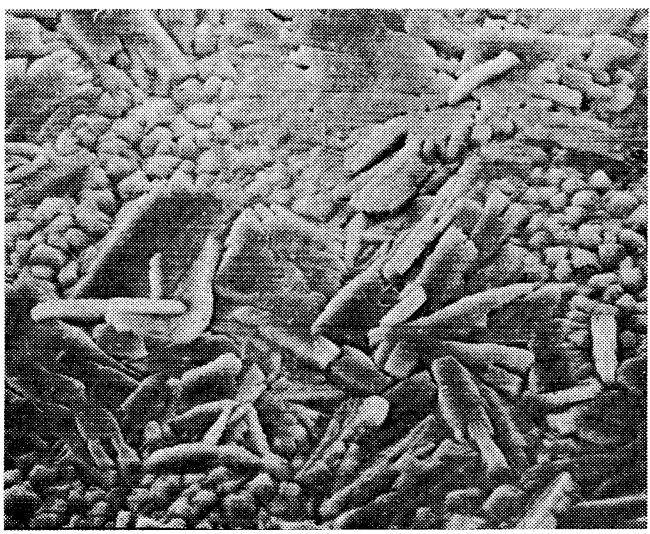

g) $\mathrm{PC}-\mathrm{C}$

$\mathrm{C} / \mathrm{W}: 2.4 \mathrm{~g} / \mathrm{m}^{2}$

$\mathrm{P}: 91 \%$

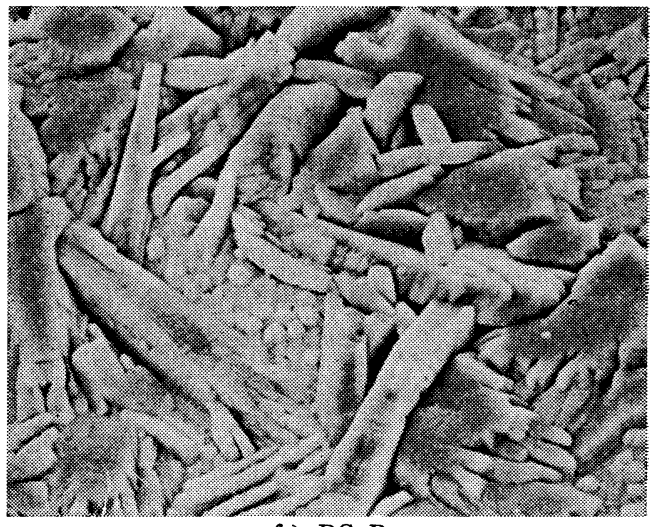

f) $\mathrm{PC}-\mathrm{B}$

$\mathrm{C} / \mathrm{W}: 2.8 \mathrm{~g} / \mathrm{m}^{2}$

P : $90 \%$

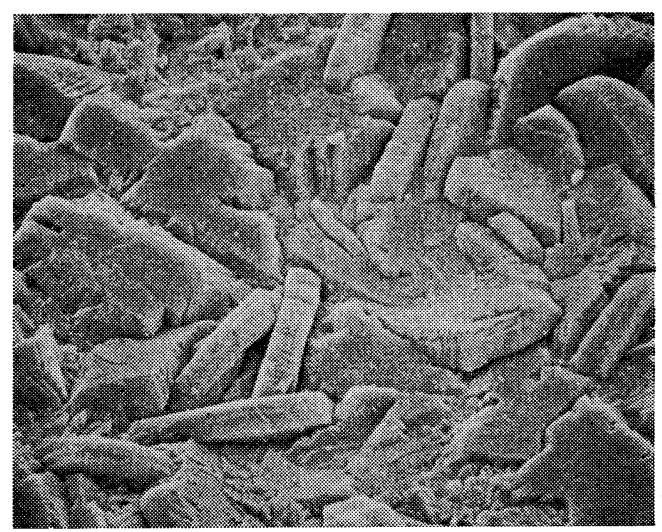

h) PC-D

$\mathrm{C} / \mathrm{W}: 2.8 \mathrm{~g} / \mathrm{m}^{2} \quad \mathrm{P}: 90 \%$

Photo. 2. Zinc phosphating property on steel side of Pre-Coated Steels that have different surface preparation $(\mathrm{SEM} \times 1,500)$

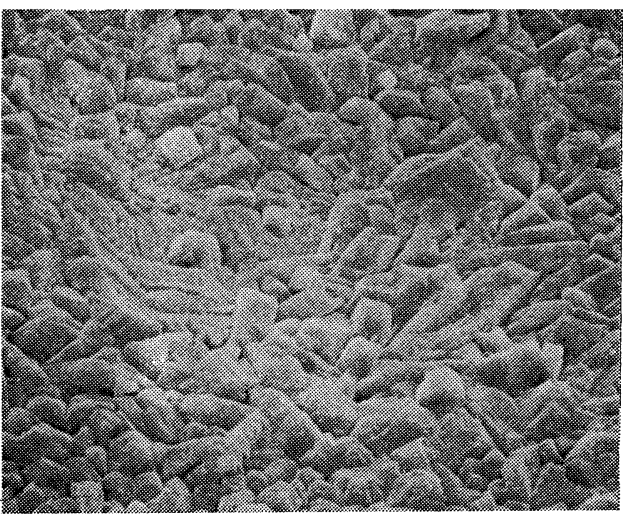

i) $\mathrm{PC}-\mathrm{E}$

$\mathrm{C} / \mathrm{W}: 2.5 \mathrm{~g} / \mathrm{m}^{2} \quad \mathrm{P}: 91 \%$

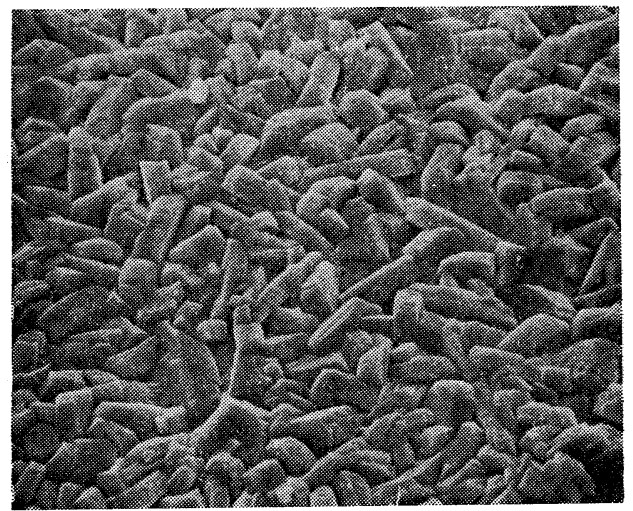

j) $\mathrm{PC}-\mathrm{F}$

$\mathrm{C} / \mathrm{W}: 2.6 \mathrm{~g} / \mathrm{m}^{2} \quad \mathrm{P}: 91 \%$

Photo. 3. Zinc phosphating property on steel side of Pre-Coated Steels that have different surface preparation $(\mathrm{SEM} \times 1,500)$ 


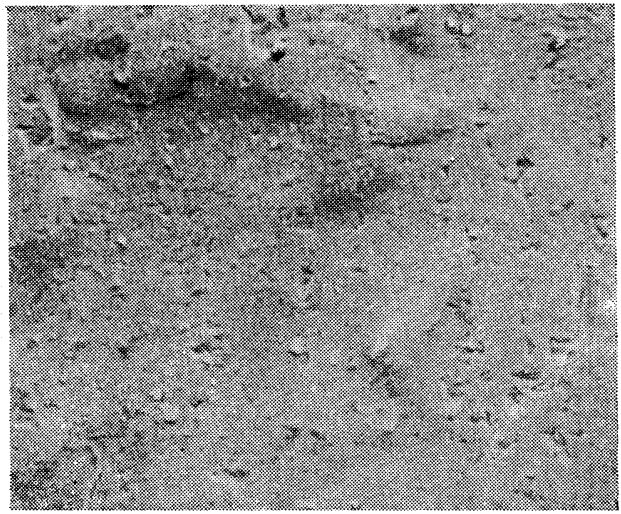

g) $\mathrm{PC}-\mathrm{C}$

$\mathrm{Ra}: 1.15 \mu \quad$ PPI $: 106$

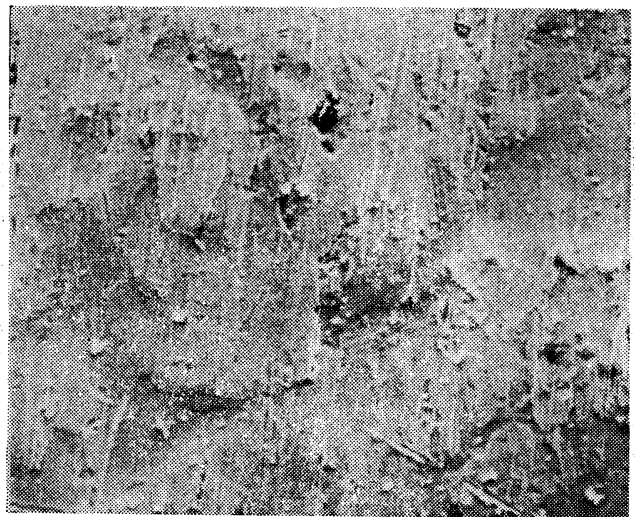

i) $\mathrm{PC}-\mathrm{E}$

Ra $: 1.10 \mu \quad$ PPI $: 118$

Photo. 4. Steel side surface profiles of Pre-Coated Steels without phosphate treatment $(\mathrm{SEM} \times 500)$

えることによって化成処理性を向上することが可能であ る。写真-3 の i ）は e ）～g ）之同一の塗装鋼板である が，冷延面の表面仕上げ方法を異にしている。すなわち e ） g ）はブラッシング方式であるが，i ）については 表面の最表層を除去してしまう研削方式である。i）の 結晶形態と結晶特性を写真 -1 の ) の冷延鋼板と対比 してもほぼ同等であることから，i）で実施した研削方 式を適用すれば冷延鋼板並の塗装鋼板冷延面が得られる ことになる。

写真-4 には表面仕上げ法の異なる鋼板 $\mathrm{g}$ ) と i ) の原 板比較を目的とした SEM と表面粗度を示した。SEM

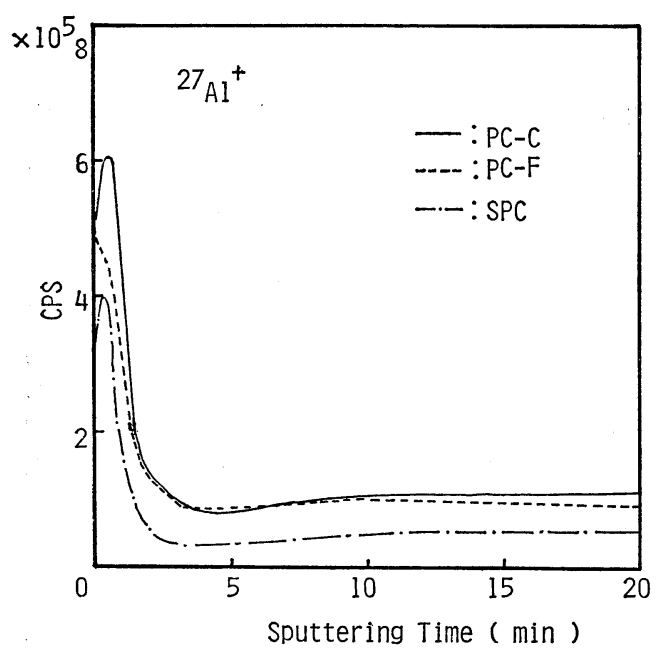

Fig. 2. Surface analysis for Al component on steel side of Pre-Coated Steels by SIMS sputtering についてみる限り，i）の研削方式が g ) のブラッシング 方式よりも荒く研ぎ落とされているようにみえる。除去 されている層厚みは確かにｉ）の方が相当厚いと思われ るが，これを表面粗度指数で比較すると汪とんど差はな い。 Ra 值は表面の平均粗さを，またPPI（Peak Per Inch）值は1インチ長さ当たり $1.25 \mu$ ピークを超える むのの個数を示した粗度指数であるが, 両者はほぼ同等 である。

また写真-3 のj）には e)〜 i ）までの鋼板とは異な る製造プロセスをもち，かつブラッシングや研削方式等 の表面仕上げを適用していない塗装鋼板について示し

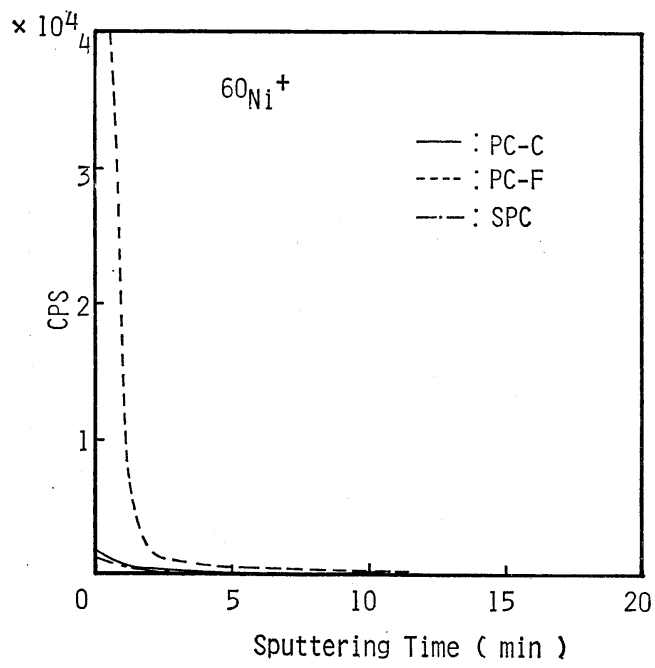

Fig. 3. Surface analysis for $\mathrm{Ni}$ component on steel side of Pre-Coated Steels by SIMS sputtering 
た。得られた結晶は緻密で質の高いものであり冷延鋼板 と同等のレベルである。このように同じ塗装鋼板でもそ の製造プロセスの相違によって化成処理性に悪影響を及 ぼさない場合もある。

そこで冷延鋼板をべースにして g) PC-C のブラッシ ング材と j ） PC-F に対し，表面分析の手法として二次 イオン質量分析 SIMS による表面成分の depth profile をとり図-2 及び図-3 に示した。図-2 は 3 種の鋼板 の冷延面に括ける $\mathrm{Al}$ 成分について, 図-3 は同様に $\mathrm{Ni}$ 成分について各々スパッターリングによる分布度を比較 したものである。この結果， $\mathrm{Al}$ 成分についてはg) PCC のブラッシング材が他の冷延鋼板及び $\mathrm{PC}-\mathrm{F}$ よりも 高いピークを示している。これは塗装鋼板製造プロセス 中の過程において $\mathrm{Al}$ 成分が熱履歴等により表面濃化を 起したため, 酸化皮膜を形成しその結果, 緻密な燐酸塩 の結晶形成を阻害したのではないかと考えられる。

一方， Ni 成分はj） PC-F に括いて他の冷延鋼板及 び PC-C のブラッシング材よりも著しく表面に存在し ていることが確認できる。j） PC-F の場合には原板冷 延鋼板に片面 $\mathrm{Zn}-\mathrm{Ni}$ 合金化メッキをあらかじめ実施し， そのメッキ層上にジンクリッチプライマー塗膜を形成す る塗装鋼板である。したがって合金メッキ層形成過程で 冷延面側は $\mathrm{Zn} / \mathrm{Ni}$ 成分の影響を受けると考えられる。 $\mathrm{Zn}$ 成分は $\mathrm{EG}$ 材の冷延面での影響について述べたよう 飞, 化成処理性に悪影響を及ぼすことから電気化学的処
理により除去される。この場合 $\mathrm{Ni}$ は $\mathrm{Zn}$ 及び $\mathrm{Fe}$ より も電位的に貴であるため鋼板表面に残留し，その結果 図-3 でみられるように著しい存在 ピークを示すものと 考えられる。鋼板表面の Ni はその表面濃度にもよる が，一般的には（5）式の Fe 供給を促進する成分であ る。メッキ過程後の焼付け塗装工程を経た冷延面の化成 処理性が良好な理由は，主にこの Ni 成分の寄与が効果 を発揮しているためと考兄らる。

$$
\text { 文献 }
$$

1）小嶋隆司, 岡部正良, 置田 宏: 防食落術, 30, 580 (1981)

2）広瀬祐輔，内田和子：防食技術，31，782（1982）

3）前田重義：防食技術，32，37（1983）

4）前田重義, 浅井恒敏, 新井信一，鈴木堅市：鉄と 鋼, 68 [16], 2497 (1982)

5）若野 茂, 薄木智亮, 西原 実, 藤野允克 : 鉄之 鋼, 66[7], 945 (1980)

6）玉井康勝，森 誠之：金属表面技術，31 [9], 482 (1980)

7）梅原誠一郎, 盛屋喜夫, 松島安信 : 鉄と鋼, 68 [7], 720 (1982)

8）前田重義：実務表面技術，31 [3]，95（1984）

9）佐藤 登：防食技術，32，379（1983）

10）置田 宏，松島安信：塗装工学, 18 [11]，478 (1983)

11) T. Yoshihara, H. Okita: Transactions ISIJ, 23, 984 (1983)

\title{
The Surface Characterization Effect of Steel for Automobile Relating to Zinc Phosphating Property
}

\author{
Noboru SAтон* \\ * Honda Motor Co., Ltd. Suzuka Factory \\ 1907, Hirata-cho, Suzuka-shi, Mie Pref., 513 Japan
}

Abstract

Regarding the zinc phosphating property on steel surface side of One-side Electrolytic Galvanized Steel (EG) and One-side Pre-Coated Steel (PC) for Automobile, surface characterization effect was studied.

In case of EG, though the zinc concentration on steel surface influences the zinc phosphatability, the electrochemical treatment of zinc removal is valid for good phosphating.

In case of PC, steel surface receives the hysteresis in the zinc-rich primer baking process, so that it influences the zinc phosphatability. However, the certain surface preparation will improve the phosphatability of the surface as the same level as cold rolled steel. There is an exceptional PC which shows the good phosphatability without surface preparation. This phenomenon will be owing to the $\mathrm{Ni}$ component as surface characterization. 